\title{
Analysis of Submarine with the Study of Mechanical Investigations using Borei - Class Submarine Model
}

\author{
Amit Kumar Mehar \\ Associate Professor, Mechanical Engineering \\ Raghu Engineering College (Autonomous) \\ Andhra Pradesh, India
}

\author{
Potoju Muralidhar \\ Mechanical Engineering \\ Raghu Engineering College (Autonomous) \\ Andhra Pradesh, India
}

\begin{abstract}
In this current era of globalization every prosperous country in the world are wishes to develop a high technological machine-like nuclear-powered submarine, long ranging missile equipped submarines etc. To increase their navel strength and force for their countries pride. Even a highly equipped and technologically advanced submarine got damaged due to the collisions with mountain rocks, or ice bergs in ocean / sea. Sometimes these collisions lead to critical damage of parts of submarine, or injuries to soldiers. In this research work, modelling of a Borei - class submarine models are done by using a modelling software, CATIA V5. Various investigations and their analysis done by using ANSYS CFD \& ANYSYS Explicit Dynamics By using ANSYS the analyzed parameters are drag force, drag coefficient, lift Force, lift coefficient, deformation, total velocity, total acceleration, equivalent stress, maximum principal stress, minimum principal stress, maximum shear. stress, stress intensity, equivalent strain, maximum principal elastic strain, minimum principal elastic strain, maximum shear elastic strain, elastic strain intensity.
\end{abstract}

Keywords - Borei-class submarine, CATIA, ANSYS, CFD, Explicit Dynamics, Drag, Lift, Deformation, Stress, Strain, Streamlines, Velocity, Acceleration.

\section{INTRODUCTION}

A ship powered by atomic energy is called nuclear submarine that travels primarily under-water, but also on the surface of the ocean. previously conventional submarines used diesel engines that required air for moving on the surface of the water, and battery - powered electric motors for moving beneath it. The limited lifetime of electric batteries meant that even the most advanced conventional submarine could only remain submerged for a few days at slow speed, and only a few hours at top speed. On the other hand, nuclear submarines can remain under-water for several months. This ability, combined with advanced weapons technology, makes nuclear submarines one of the most useful warships ever built. [1-3]

$$
\text { I. SHIP STRUCTURE AND PARTS }
$$

A Submarine has Outer hull and inner hull which is made of different material alloys Like Hy80 or Titanium Harden steel, etc. inner hull protects the crew from the water pressure bearing down on the submarine in the outer hull provides a streamlined shape to the submarine.

C. Trim tanks: These are in the front part and aft (rearward) sections of the submarine, which are also able to take on or release water in order to keep the submarine's weight equally distributed.

D. Rudder: These are vertically aligned, to submarine and by moving it, the ship can be directed side-to-side.
E. Stern planes: are horizontally aligned, so that moving them will guide the submarine's movement upward or downward.

F. Propeller: These powered by the steam-driven turbine and generators. The steam is created by the nuclear reactor. G. Nuclear Reactor: These are essentially a glorified steam engine. It's usually located in the rear portion of the submarine. The reactor is protected by a thick metal casing that weighs around 100 tons. A specially designed alloy inside this shielding further protects the radioactive fuel rods.

H. Sonar sphere: it is located in the Front part of the submarine. Sonar helps a submarine detect other objects in the water. It works by sending out a sound wave. If this sound wave strikes an object, a portion of the sound will be echoed back to the sub.

I. Torpedo room: is where all torpedoes are stored and loaded into torpedo tubes to prepare them for launching.

J. Mess deck: Forward compartment: submarine's crew is housed and fed in very tight, efficient quarters called the berthing and mess deck. Usually, this area is in the middle level of the ship's forward compartment.

\section{NUCLEAR SUBMARINE ATMOSPHERE}

Nuclear Powered Submarines is particularly suitable for vessels which need to be at sea for long periods without refueling. In Nuclear Powered Submarines are submariners live and work in an atmosphere composed of approximately $80 \%$ naturally occurring nitrogen, $19 \%$ oxygen (manufactured aboard ship), and a complex mixture of inorganic and organic contaminants. The concentrations of contaminants exist as a balance between the rates of production from human and operational activities and the rate of removal by engineering systems. The biological effects of inorganic gases, particularly carbon dioxide, have been extensively studied. Investigators are now attempting to define the composition and concentration of volatile organic compounds that accumulate during 90-day submergences. Medical studies have not conclusively shown that crewmembers incur adverse health effects from continuous exposures to the sealed atmospheres of nuclear submarines. In future, constraints on fossil fuel use in transport may bring marine nuclear propulsion into more widespread use. So far, exaggerated fears about safety have caused political restriction on port access [4-9] 
III.

\section{BOREI-CLASS SUBMARINE MODEL DESIGN AND ANALYSIS.}

Using the CATIA Design software and prepare the Borei class submarine model.

This Borei - class submarine model was design in Catia and after modelling the submarine it is imported to ANSYS.

In ANSYS There is two types tests are conducted on submarine

\section{A. ANSYS CFD Analysis \\ B. ANSYS Explicit Dynamics}

\section{A. ANSYS CFD Analysis}

In this research work CFD analysis done at Borei - class submarine model and find the Pressure Effect, Velocity Effect, Drag force, Drag Coefficient, Lift force, Lift coefficient, Streamlines, Volume Rendering, at Different velocities and compare the different at different velocities $500 \mathrm{~m} / \mathrm{s}, 1000 \mathrm{~m} / \mathrm{s}, 1500 \mathrm{~m} / \mathrm{s}$. and find the results of all these parameters effect on the submarine. [10-14]

\section{B. ANSYS Explicit Dynamics}

In this research work Explicit Dynamics analysis done at Borei - class submarine model and find the deformation, total velocity, total acceleration, equivalent stress, maximum principal stress, minimum principal stress, maximum shear. [15-17]

\section{ABOUT BOREI-CLASS SUBMARINE:}

The new design for this Borei class submarine carries Bulava submarine-launched ballistic missiles. Boreiclass submarine was planned to launch in 2009 but due to delay of Bulava development and fitted in 2013. There is lot of failures during test launches by 2017 out of 27 tests 12 were failure Development of missiles continues.

\begin{tabular}{|l|l|}
\hline Country of origin & Russia \\
\hline Entered service & 2012 \\
\hline Crew & $130 \mathrm{men}$ \\
\hline Diving depth (operational) & $380 \mathrm{~m}$ \\
\hline Diving depth (maximum) & $400-450 \mathrm{~m}$ \\
\hline Sea endurance & $90-100$ days \\
\hline
\end{tabular}

\section{Dimensions and displacement}

\begin{tabular}{|l|l|}
\hline Length & $160 \mathrm{~m}$ \\
\hline Beam & $13.5 \mathrm{~m}$ \\
\hline Draught & $10 \mathrm{~m}$ \\
\hline Surfaced displacement & 14720 tons \\
\hline Submerged displacement & 24000 tons \\
\hline
\end{tabular}

Propulsion and speed

\begin{tabular}{|l|l|}
\hline Surfaced speed & 15 knots \\
\hline Submerged speed & $26-29$ knots \\
\hline Propulsion & $\begin{array}{l}\text { nuclear reactor and pump } \\
\text { jet propulsion }\end{array}$ \\
\hline
\end{tabular}

Armament

\begin{tabular}{|l|l|}
\hline Missiles & $16 \times$ Bulava SLBMs \\
\hline Torpedoes & $6 \times 533 \mathrm{~mm}$ torpedo tubes \\
\hline
\end{tabular}

\section{Pressure:}

\section{Analysis of Borei-class submarine:}

The pressure at $500 \mathrm{~m} / \mathrm{s}, 1000 \mathrm{~m} / \mathrm{s}, 1500 \mathrm{~m} / \mathrm{s}$ velocity:
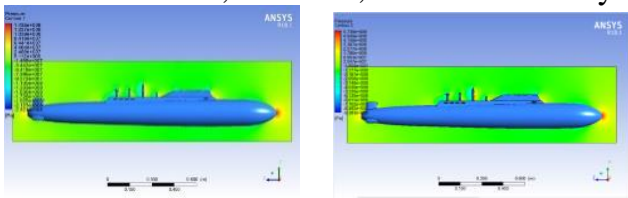

fig: 1 pressure at $500 \mathrm{~m} / \mathrm{s}$ fig: 2 pressure at $1000 \mathrm{~m} / \mathrm{s}$

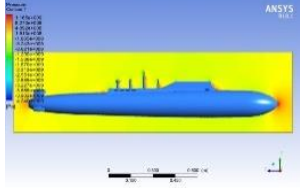

Fig: 3 pressure at $1500 \mathrm{~m} / \mathrm{s}$

velocity:

velocity effect at $500 \mathrm{~m} / \mathrm{s}, 1000 \mathrm{~m} / \mathrm{s}, 1500 \mathrm{~m} / \mathrm{s}$.

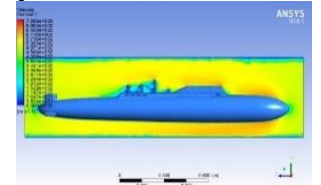

fig: 4 velocity at $500 \mathrm{~m} / \mathrm{s}$

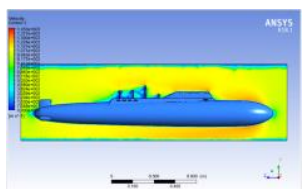

fig: 5 velocity at $1000 \mathrm{~m} / \mathrm{s}$

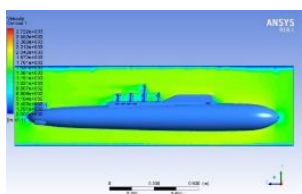

Fig: 6 velocity at $1500 \mathrm{~m} / \mathrm{s}$

\section{Velocity streamlines}

An important concept in the study of hydrodynamics concerns the idea of streamlines. The below figure shows that velocity streamlines at $500 \mathrm{~m} / \mathrm{s}$ striking on the Boreiclass submarine model.

\section{Velocity streamlines at $500 \mathrm{~m} / \mathrm{s}, 1000 \mathrm{~m} / \mathrm{s}, 1500 \mathrm{~m} / \mathrm{s}$}

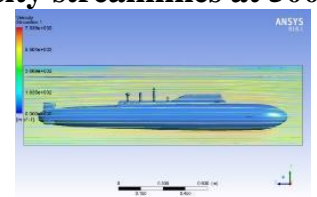

fig: 7 streamlines $500 \mathrm{~m} / \mathrm{s}$

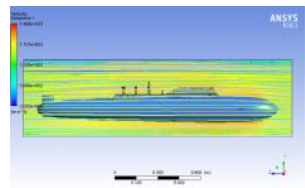

fig: 8 streamlines $1000 \mathrm{~m} / \mathrm{s}$

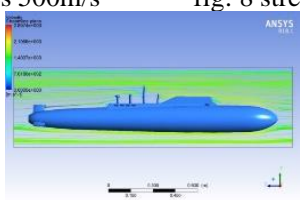

Fig: 9 streamlines $1500 \mathrm{~m} / \mathrm{s}$

\section{volume rendering}

Volume rendering shows that the body Borei-class submarine. The enclosure applied on the body is suitable or not can be visualize in this volume rendering. 


\section{Volume rendering at velocity $500 \mathrm{~m} / \mathrm{s}, 1000 \mathrm{~m} / \mathrm{s}, 1500 \mathrm{~m} / \mathrm{s}$}

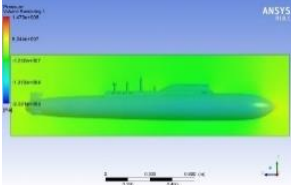

Fig: 10 volume rendering $500 \mathrm{~m} / \mathrm{s}$ at $1000 \mathrm{~m} / \mathrm{s}$

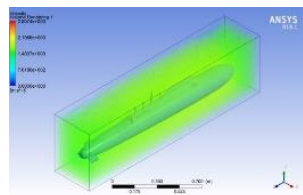

Fig: 12 volume rendering at $1500 \mathrm{~m} / \mathrm{s}$

\section{Explicit Dynamics}

Compression with same velocity at 8.09935 knots and same collision time $10000 \mathrm{~s}$ with changing fixed supports.

\section{Deformation}

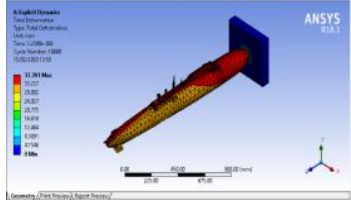

fig 16.Deformation of top fixed supports

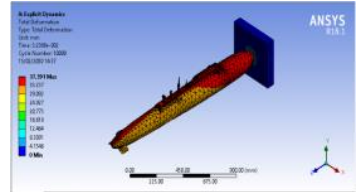

fig 17.Deformation of both side fixed support Time [s] $[$ Minimum [mm] $\mid$ Maximum [mm

\begin{tabular}{|c|c|c|c|c|c|}
\hline \multirow{3}{*}{$\frac{\frac{\text { Time }[\mathrm{s}]}{1.1755 \mathrm{e}-038}}{3.2389 \mathrm{e}-002}$} & Minimum [mm] & Maximum [mm] & Time [s] & Minimum [mm & Maximum [mm] \\
\hline & \multirow[b]{2}{*}{0.} & 0. & $1.1755 \mathrm{e}-038$ & \multirow{2}{*}{0.} & 0. \\
\hline & & 37.391 & $3.2389 \mathrm{e}-002$ & & 37.391 \\
\hline
\end{tabular}

Table 1
The deformation of the submarine analyzed at velocity of 8.09935 knots, found that deformation is independent of fixed supports

Total velocity

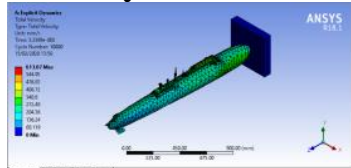

fig 18. Total velocity of

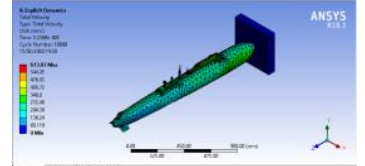

fig 19 . Total velocity of
Top fixed support

both side fixed support

\begin{tabular}{|c|c|c|c|c|c|}
\hline Time [s] & Minimum [mm/s & Maximum [mm/s] & Time [s] & Minimum $[\mathrm{mm} / \mathrm{s}]$ & Maximum $[\mathrm{mm} / \mathrm{s}]$ \\
\hline $1.1755 \mathrm{e}-038$ & \multirow{2}{*}{0.} & 4166.7 & \multirow{2}{*}{\begin{tabular}{|l|}
$1.1755 \mathrm{e}-038$ \\
$3.2389 \mathrm{e}-002$ \\
\end{tabular}} & \multirow[b]{2}{*}{0.} & 4166.7 \\
\hline $3.2389 \mathrm{e}-002$ & & 613.07 & & & 613.07 \\
\hline
\end{tabular}

The total velocity of the submarine analyzed at velocity of 8.09935 knots, found that total velocity is independent of fixed supports

\section{Total acceleration}

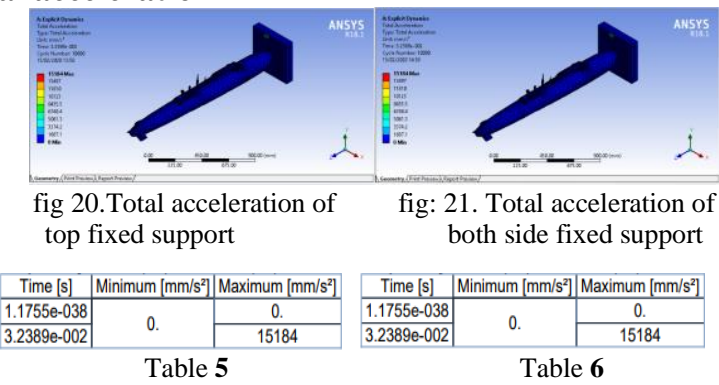

The total acceleration of the submarine analyzed at velocity of 8.09935 knots, found that total acceleration is independent of fixed supports.
Equivalent elastic stress

\begin{tabular}{|c|c|c|}
\hline \multicolumn{3}{|c|}{$\begin{array}{l}\text { i.Equivalent stress of } \\
\text { top fixed support }\end{array}$} \\
\hline Time [s] & Minimum [MPa & Maximum [MPa] \\
\hline $1755 \mathrm{e}-038$ & \multirow{2}{*}{ 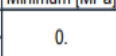 } & 0. \\
\hline $2389 \mathrm{e}-002$ & & 17.802 \\
\hline
\end{tabular}

ii. Equivalent stress of both side fixed support

\begin{tabular}{|c|c|c|}
\hline Time $[\mathrm{s}]$ & Minimum [MPa] & Maximum [MPa] \\
\cline { 1 - 1 } $1.1755 \mathrm{e}-038$ & 0. & 0. \\
\hline $3.2389 \mathrm{e}-002$ & 0. & 17.802 \\
\hline
\end{tabular}

The equivalent stress of the submarine analyzed at velocity of 8.09935 knots, found that equivalent stress is independent of fixed supports

Maximum principal stress

I.Maximum principal stress

of top fixed support

ii. Maximum principal stress

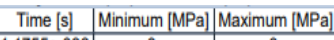

\begin{tabular}{|c|c|c|}
\hline $1.1755 \mathrm{e}-038$ & 0. & 0. \\
\hline $3.2389 \mathrm{e}-002$ & 0.461 & 4.5418 \\
\hline
\end{tabular}

\begin{tabular}{l|l|l}
\hline $3.2389 \mathrm{e}-002$ & -0.461 & 4.5418 \\
\hline
\end{tabular}

Table 9

Time [s] Minimum [MPa] $\mid$ Maximum [MPa] \begin{tabular}{c|c|c}
\hline $1.1755 \mathrm{e}-038$ & 0. & 0. \\
\hline
\end{tabular}

\begin{tabular}{|c|c|c|}
\hline $3.2389 \mathrm{e}-002$ & -0.461 & 4.5418 \\
\hline
\end{tabular}

Table 10

The maximum principal stress of the submarine analyzed at velocity of 8.09935 knots, maximum principal stress found that is independent of fixed supports

Minimum principal stress

I. Minimum principal stress ii. Minimum principal stress of top fixed support both side fixed support

\begin{tabular}{|c|c|c|c|c|c|}
\hline Time [s] & Minimum [MPa] & Maximum [MPa] & Time [s] & Minimum [MPa] & Maximum [MPa \\
\hline $1.1755 \mathrm{e}-038$ & 0. & 0. & $1.1755 \mathrm{e}-038$ & 0. & 0. \\
\hline $3.2389 \mathrm{e}-002$ & -16.03 & 1.035 & $3.2389 \mathrm{e}-002$ & -16.03 & 1.035 \\
\hline
\end{tabular}

The minimum principal stress of the submarine analyzed at velocity of 8.09935 knots, minimum principal stress found that is independent of fixed supports

Maximum shear stress

I. Maximum shear stress of top fixed support

\begin{tabular}{|c|c|c|}
\hline Time $[\mathrm{s}]$ & Minimum [MPa] & Maximum [MPa] \\
\hline $1.1755 \mathrm{e}-038$ & 0. & 0. \\
\cline { 3 - 3 } $3.2389 \mathrm{e}-002$ & 0.1588 \\
\hline \multicolumn{3}{|c|}{ Table 13 } \\
\hline
\end{tabular}

i. Maximum shear stress of both side fixed support

\begin{tabular}{|c|c|c|}
\hline Time $[\mathrm{s}]$ & Minimum [MPa] & Maximum [MPa] \\
\hline $1.1755 \mathrm{e}-038$ & 0. & 0. \\
\cline { 3 - 3 } $3.2389 \mathrm{e}-002$ & 0.1588 \\
\hline \multicolumn{3}{|c|}{ Table 14 }
\end{tabular}

The maximum shear stress of the submarine analyzed at velocity of 8.09935 knots, maximum shear stress found that is independent of fixed supports

Stress intensity

I.Stress intensityof ii. Stress intensityof top fixed support both side fixed support

\begin{tabular}{|c|c|c|c|c|c|}
\hline \multirow{3}{*}{$\frac{\frac{\text { Time }[\mathrm{s}]}{1.1755 \mathrm{e}-038}}{3.2389 \mathrm{e}-002}$} & Minimum [MPa & Maximum [MPa] & Time $[\mathrm{s}]$ & Minimum [MPa] & Maximum [MPa] \\
\hline & \multirow[b]{2}{*}{0.} & 0. & \multirow{2}{*}{\begin{tabular}{|l|}
$1.1755 \mathrm{e}-038$ \\
$3.2389 \mathrm{e}-002$ \\
\end{tabular}} & \multirow[b]{2}{*}{0.} & 0. \\
\hline & & 18.318 & & & 18.318 \\
\hline
\end{tabular}

Table 5.15

Table 5.16

The stress intensity of the submarine analyzed at a velocity of 8.09935 knots, stress intensity found that is independent of fixed supports

Equivalent elastic strain

\begin{tabular}{|c|c|c|c|c|c|}
\hline & \multicolumn{2}{|c|}{$\begin{array}{l}\text { i.Equivalent strain of } \\
\text { top fixed support }\end{array}$} & \multicolumn{3}{|c|}{$\begin{array}{l}\text { ii. Equivalent strain of } \\
\text { both side fixed support }\end{array}$} \\
\hline Time [s] & Minimum [mm/mm & Maximum [mm/mm] & Time $[\mathrm{s}]$ & Minimum $[\mathrm{mm} / \mathrm{mm}]$ & Maximum [mm/mm] \\
\hline $1.1755 \mathrm{e}-038$ & \multirow[t]{2}{*}{0.} & 0. & \multirow{2}{*}{\begin{tabular}{|l|}
$1.1755 \mathrm{e}-038$ \\
$3.2389 \mathrm{e}-002$ \\
\end{tabular}} & \multirow[t]{2}{*}{0} & 0. \\
\hline $3.2389 \mathrm{e}-002$ & & 0.13397 & & & 0.13397 \\
\hline
\end{tabular}

The equivalent strain of the submarine analyzed at velocity of 8.09935 knots, found that equivalent strain is independent of fixed supports

\section{Maximum principal elastic strain}

I. Maximum principal elastic ii. Maximum principal elastic strain strain of top fixed support of both side fixed support

\begin{tabular}{|c|c|c|c|c|c|}
\hline Time [s] & Minimum [mm/mm] & Maximum [mm/mm] & Time $[\mathrm{s}]$ & Minimum [mm/mm] & Maximum [mm/mm] \\
\hline 1.1755e-038 & 0. & 0 . & \begin{tabular}{|l|l|}
$1.1755 \mathrm{e}-038$ \\
\end{tabular} & 0. & 0 . \\
\hline $3.2389 \mathrm{e}-002$ & $1.2499 \mathrm{e}-006$ & $9.5979 \mathrm{e}-002$ & \begin{tabular}{|l|}
$3.2389 \mathrm{e}-002$ \\
\end{tabular} & $1.2499 \mathrm{e}-006$ & $9.5979 \mathrm{e}-002$ \\
\hline
\end{tabular}


The maximum principal elastic strain of the submarine analyzed at velocity of 8.09935 knots, found that maximum principal elastic strain is independent of fixed supports

\section{Minimum principal elastic strain}

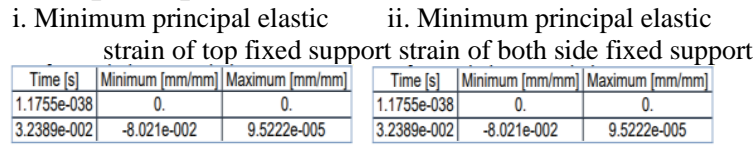

Table 22

Table 21$$
\begin{array}{|c|c|c|}
\hline .2389--002 & -8.021 e-002 & 9.5222-005 \\
\hline
\end{array}
$$

The minimum principal elastic strain of the submarine analyzed at a velocity of 8.09935 knots, found that minimum principal elastic strain is independent of fixed supports.

\section{Maximum shear elastic strain}

Maximum shear elastic strain ii. Maximum shear elastic strain of top fixed support

\begin{tabular}{|c|c|c|}
\hline Time $[\mathrm{s}]$ & Minimum $[\mathrm{mm} / \mathrm{mm}]$ & Maximum $[\mathrm{mm} / \mathrm{mm}]$ \\
\hline $1.1755 \mathrm{e}-038$ & 0. & 0. \\
\hline
\end{tabular}

\begin{tabular}{c|c|c|}
\hline $32389 \mathrm{e}-002$ & $8.516 \mathrm{e}-006$ & 0.16484 \\
\hline
\end{tabular}

Table 23 of both side fixed support

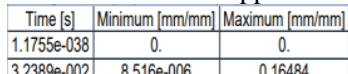

\begin{tabular}{c|c|c|}
\hline $3.2389 \mathrm{e}-002$ & $8.516 \mathrm{e}-006$ & 0.16484 \\
\hline
\end{tabular}

Table 24

The maximum shear elastic strain of the submarine analyzed at velocity of 8.09935 knots, found that maximum shear elastic strain is independent of fixed supports.

\section{Elastic strain intensity}

\begin{tabular}{|c|c|c|c|c|c|}
\hline \multicolumn{3}{|c|}{$\begin{array}{l}\text { i. Elastic strain intensity of } \\
\text { Top fixed support }\end{array}$} & \multicolumn{3}{|c|}{$\begin{array}{l}\text { ii. Elastic strain intensity of } \\
\text { both side fixed support }\end{array}$} \\
\hline Time $[\mathrm{s}]$ & Minimum [mm/mm] & Maximum [mm/mm] & Time $[\mathrm{s}]$ & Minimum [mm/mm] & Maximum [mm/mm] \\
\hline $1.1755 \mathrm{e}-038$ & 0. & 0. & $1.1755 \mathrm{e}-038$ & 0. & 0. \\
\hline $3.2389 \mathrm{e}-002$ & $8.516 \mathrm{e}-006$ & 0.16484 & $3.2389 \mathrm{e}-002$ & $8.516 \mathrm{e}-006$ & 0.16484 \\
\hline
\end{tabular}

The elastic strain intensity of the submarine analyzed at velocity of 8.09935 knots, found that elastic strain intensity is independent of fixed supports.

Comparing the top fixed support at velocity 8.09935 knots with same velocity changing the fixed supports and increases the collision time from $10000 \mathrm{~s}$ to $1000000 \mathrm{~s}$.

\section{Deformation}

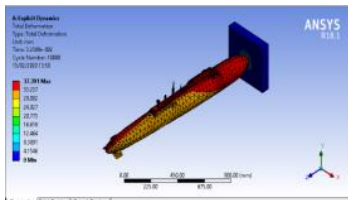

Fig 22.Deformation of

Top fixed supports

Time [s] $\quad$ Minimum [mm] $\mid$ Maximum [mm

$1.1755 \mathrm{e}-038$

$3.2389 \mathrm{e}-002$

Table 27

\begin{tabular}{l|c|}
0. & 0. \\
\cline { 2 - 2 } & 37.391 \\
\hline & Table 28
\end{tabular}

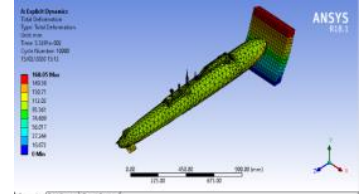

fig 23. Deformation of bottom fixed support Time $[\mathrm{s}] \quad$ Minimum [mm] $\mid$ Maximum [mm] \begin{tabular}{ll|r|}
$1.1755 \mathrm{e}-038$ & \multirow{2}{*}{0.} & 0. \\
$3.32910-002$ & & 168.05
\end{tabular}
The deformation of the submarine analyzed at velocity of 8.09935 knots and comparing with changing the fixed support and increasing collision time from $10000 \mathrm{~s}$ to $1000000 \mathrm{~s}$, found that deformation is high compare less collision time

\section{Total velocity}

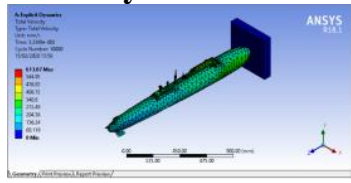

Fig 24.Total velocity of

Top fixed support \begin{tabular}{c|c|c|c|}
\hline Time $[\mathrm{s}]$ & Minimum [mm/s] & Maximum [mm/s] \\
\hline $1755 e-038$ & 0.766 .7
\end{tabular} \begin{tabular}{|l|l|r|}
\hline $1.1755 \mathrm{e}-038$ & \multirow{2}{*}{0.} & 4166.7 \\
\cline { 3 - 3 } $3.2389 \mathrm{e}-002$ & & 613.07 \\
\hline
\end{tabular}

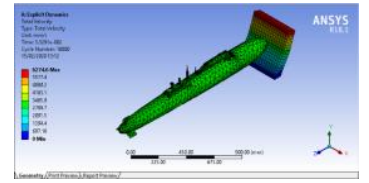

fig 25. Total velocity bottom fixed support

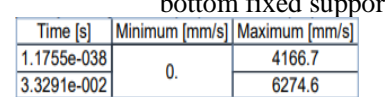

Table 30
The total velocity of the submarine analyzed at velocity of 8.09935 knots and comparing with changing the fixed support and increasing collision time from $10000 \mathrm{~s}$ to $1000000 \mathrm{~s}$, found that total velocity is high compare to less collision time

Total acceleration

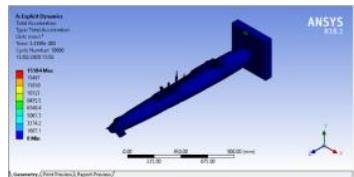

Fig 26. Total acceleration of top fixed support

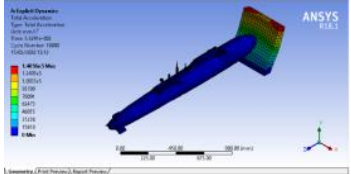

fig 27. Total acceleration of bottom fixed support

\begin{tabular}{|c|c|c|c|c|c|c|}
\hline Time $[\mathrm{s}]$ & Minimum $\left[\mathrm{mm} / \mathrm{s}^{2}\right]$ & Maximum $\left[\mathrm{mm} / \mathrm{s}^{2}\right]$ & & Time $[\mathrm{s}]$ & Minimum $\left[\mathrm{mm} / \mathrm{s}^{2}\right]$ & Maximum $\left[\mathrm{mm} / \mathrm{s}^{2}\right]$ \\
\hline $1.1755 \mathrm{e}-038$ & \multirow{2}{*}{0.} & 0. & $1.1755 \mathrm{e}-038$ & 0. & 0. \\
\cline { 6 - 7 } & & 15184 & $3.3291 \mathrm{e}-002$ & & $1.4056 \mathrm{e}+005$ \\
\hline
\end{tabular}

Table 31

Table 32

The total acceleration of the submarine analyzed at velocity of 8.09935 knots and comparing changing the fixed support and with increasing collision time from $10000 \mathrm{~s}$ to 1000000 $\mathrm{s}$, found that total acceleration is less compare to less collision time

\section{Equivalent elastic stress}

\begin{tabular}{|c|c|c|c|c|c|}
\hline \multicolumn{3}{|c|}{$\begin{array}{l}\text { i.Equivalent stress of } \\
\text { top fixed support }\end{array}$} & \multicolumn{3}{|c|}{$\begin{array}{l}\text { ii. Equivalent stress of } \\
\text { both bottom support }\end{array}$} \\
\hline Time $[\mathrm{s}]$ & Minimum [MPa & Maximum [MPa] & Time [s] & Minimum [MPa & Maximum [MPa] \\
\hline $1.1755 \mathrm{e}-038$ & \multirow{2}{*}{0.} & 0. & $1.1755 \mathrm{e}-038$ & \multirow[t]{2}{*}{ (2) } & 0. \\
\hline $3.2389 \mathrm{e}-002$ & & 17.802 & $3.3291 \mathrm{e}-002$ & & 9.2819 \\
\hline
\end{tabular}

The equivalent elastic stress of the submarine analyzed at a velocity of 8.09935 knots and comparing with changing the fixed support and increasing collision time from $10000 \mathrm{~s}$ to $1000000 \mathrm{~s}$, found that equivalent elastic stress is less compare with less collision time

\section{Maximum principal stress}

\begin{tabular}{|c|c|c|c|c|c|}
\hline \multicolumn{3}{|c|}{$\begin{array}{c}\text { I.Maximum principal stress } \\
\text { of top fixed support }\end{array}$} & \multicolumn{3}{|c|}{$\begin{array}{l}\text { ii. Maximum principal stress } \\
\text { of bottom fixed support }\end{array}$} \\
\hline Time $[\mathrm{s}]$ & Minimum [MPa] & Maximum [MPa] & Time $[\mathrm{s}]$ & Minimum [MPa] & Maximum [MPa] \\
\hline $1.1755 \mathrm{e}-038$ & 0. & 0. & $1.1755 \mathrm{e}-038$ & 0. & 0. \\
\hline $3.2389 \mathrm{e}-002$ & -0.461 & 4.5418 & $3.3291 \mathrm{e}-002$ & -1.6122 & 4.0823 \\
\hline
\end{tabular}

Table 35 Table 36

The maximum principal stress of the submarine analyzed at a velocity of 8.09935 knots and comparing with changing the fixed support and increasing collision time from $10000 \mathrm{~s}$ to $1000000 \mathrm{~s}$, found that maximum principal stress is high compare with less collision time

\section{Minimum principal stress}

I.Minimum principal stress of ii. Minimum principal stress of top fixed support

\begin{tabular}{|c|c|c|}
\hline Time $[\mathrm{s}]$ & Minimum [MPa] & Maximum [MPa] \\
\hline $1.1755 \mathrm{e}-038$ & 0. & 0. \\
\hline $3.2389 \mathrm{e}-002$ & -16.03 & 1.035 \\
\hline 37 & \multicolumn{3}{c}{ Table 38} \\
\hline
\end{tabular}
bottom fixed support

Table 37 \begin{tabular}{c|c|c|}
\hline Time $[\mathrm{s}]$ & Minimum $[\mathrm{MPa}]$ & Maximum [MPa] \\
\hline $1.175 e-038$ &
\end{tabular} \begin{tabular}{|c|c|}
\hline $1.1755 \mathrm{e}-038$ & 0. \\
\hline $3.329-002$ & -934
\end{tabular} \begin{tabular}{|c|c|c|}
\hline $3.3291 \mathrm{e}-002$ & -9.34 & 0.75162 \\
\hline
\end{tabular}

The minimum principal stress of the submarine analyzed at a velocity of 8.09935 knots and comparing with changing the fixed support and increasing collision time from $10000 \mathrm{~s}$ to $1000000 \mathrm{~s}$, found that minimum principal stress is low compare with less collision time

\section{Maximum shear stress}

\begin{tabular}{|c|c|c|c|c|c|}
\hline \multicolumn{3}{|c|}{$\begin{array}{c}\text { I. Maximum shear stress of } \\
\text { top fixed support }\end{array}$} & \multicolumn{3}{|c|}{$\begin{array}{l}\text { ii. Maximum shear stress o } \\
\text { bottom fixed support }\end{array}$} \\
\hline Time [s] & Minimum [MPa & Maximum [MPa] & Time $[\mathrm{s}]$ & Minimum [MPa] & Maximum [MPa] \\
\hline $1.1755 \mathrm{e}-038$ & \multirow{2}{*}{0.} & 0. & $1.1755 \mathrm{e}-038$ & \multirow{2}{*}{0.} & 0. \\
\hline $3.2389 \mathrm{e}-002$ & & 9.1588 & $3.3291 \mathrm{e}-002$ & & 4.8786 \\
\hline
\end{tabular}

The maximum shear stress of the submarine analyzed at a velocity of 8.09935 knots and comparing with changing the fixed support and increasing collision time from $10000 \mathrm{~s}$ to $1000000 \mathrm{~s}$, found that maximum shear stress is low compare with less collision time 


\section{Stress intensity}

\begin{tabular}{|c|c|c|c|c|c|}
\hline \multicolumn{3}{|c|}{$\begin{array}{l}\text { I.Stress intensityof } \\
\text { Top fixed support }\end{array}$} & \multicolumn{3}{|c|}{$\begin{array}{l}\text { ii. Stress intensityof } \\
\text { bottom fixed support }\end{array}$} \\
\hline Time [s] & Minimum [MPa] & Maximum [MPa] & Time [s] & Minimum [MPa] & Maximum [MPa] \\
\hline $1.1755 \mathrm{e}-038$ & \multirow{2}{*}{ 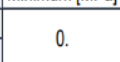 } & 0. & $1.1755 \mathrm{e}-038$ & \multirow[b]{2}{*}{0.} & 0. \\
\hline $3.2389 \mathrm{e}-002$ & & 18.318 & $3.3291 \mathrm{e}-002$ & & 9.7572 \\
\hline
\end{tabular}

The stress intensity of the submarine analyzed at a velocity of 8.09935 knots and comparing with changing the fixed support and increasing collision time from $10000 \mathrm{~s}$ to $1000000 \mathrm{~s}$, found that stress intensity is low compare with less collision time

\section{Equivalent elastic strain}

\begin{tabular}{|c|c|c|c|c|c|}
\hline \multicolumn{3}{|c|}{$\begin{array}{l}\text { i.Equivalent strain of } \\
\text { top fixed support }\end{array}$} & \multicolumn{3}{|c|}{$\begin{array}{l}\text { ii. Equivalent strain of } \\
\text { bottom support }\end{array}$} \\
\hline Time $[\mathrm{s}]$ & Minimum [mm/mm & Maximum [mm/mm] & Time [s] & Minimum [mm/mm] & Maximum [mm/mm] \\
\hline $1.1755 \mathrm{e}-038$ & \multirow{2}{*}{0.} & 0. & \multirow{2}{*}{$\frac{1.1755 \mathrm{e}-038}{3.3291 \mathrm{e}-002}$} & \multirow{2}{*}{0} & 0. \\
\hline $3.2389 \mathrm{e}-002$ & & 0.13397 & & & 0.58765 \\
\hline 43 & & & le 44 & & \\
\hline
\end{tabular}

Table 43

Table 44

The equivalent elastic strain of the submarine analyzed at a velocity of 8.09935 knots and comparing with changing the fixed support and increasing collision time from $10000 \mathrm{~s}$ to $1000000 \mathrm{~s}$, found that equivalent elastic strain is high compare with less collision time

\section{Maximum principal elastic strain}

I. Maximum principal elastic ii. Maximum principal elastic strain of top fixed support strain of bottom fixed support

\begin{tabular}{|c|c|c|c|c|c|}
\hline Time $[\mathrm{s}]$ & Minimum [mm/mm] & Maximum [mm/mm] & Time $[\mathrm{s}]$ & Minimum [mm/mm & ] Maximum [mm/mm] \\
\hline \begin{tabular}{|l|}
$1.1755 \mathrm{e}-038$ \\
\end{tabular} & 0. & 0. & $1.1755 \mathrm{e}-038$ & 0. & 0 \\
\hline $3.2389 \mathrm{e}-002$ & $1.2499 \mathrm{e}-006$ & $9.5979 \mathrm{e}-002$ & $3.3291 \mathrm{e}-002$ & 1.6334e-007 & 0.67854 \\
\hline
\end{tabular}

The maximum principal elastic strain of the submarine analyzed at a velocity of 8.09935 knots and comparing with changing the fixed support and increasing collision time, found that maximum principal elastic strain is high compare with less collision time

\section{Minimum principal elastic strain}

\begin{tabular}{|c|c|c|c|c|c|}
\hline \multicolumn{3}{|c|}{$\begin{array}{l}\text { i.Minimum principal elastic } \\
\text { strain of top fixed support }\end{array}$} & \multicolumn{3}{|c|}{$\begin{array}{l}\text { ii. Minimum principal elastic } \\
\text { strain of bottom fixed suppor }\end{array}$} \\
\hline Time [s] & Minimum [mm/mm & Maximum [mm/mm] & Time $[\mathrm{s}]$ & Minimum [mm/mm & Maximum [mm/mm] \\
\hline $1.1755 \mathrm{e}-038$ & 0. & 0. & $1.1755--038$ & 0. & 0. \\
\hline $3.2389 \mathrm{e}-002$ & $-8.021 \mathrm{e}-002$ & $9.5222 \mathrm{e}-005$ & $3.3291 \mathrm{e}-002$ & $-4.1222 \mathrm{e}-002$ & $2.0031 \mathrm{e}-003$ \\
\hline
\end{tabular}

The minimum principal elastic strain of the submarine analyzed at a velocity of 8.09935 knots and comparing with changing the fixed support and increasing collision time, found that minimum principal elastic strain is high compare with less collision time

\section{Maximum shear elastic strain}

\begin{tabular}{|c|c|c|c|c|c|}
\hline \multicolumn{3}{|c|}{$\begin{array}{l}\text { i.Maximum shear elastic strain } \\
\text { of top fixed support }\end{array}$} & \multicolumn{3}{|c|}{$\begin{array}{l}\text { ii. Maximum shear elastic strair } \\
\text { of bottom fixed support }\end{array}$} \\
\hline Time $[\mathrm{s}]$ & Minimum [mm/mm] & Maximum [mm/mm] & Time $[\mathrm{s}]$ & Minimum [mm/mm & Maximum [mm/mm] \\
\hline 1.1755e-038 & 0. & 0. & $1.1755 \mathrm{e}-038$ & 0. & 0. \\
\hline $3.2389 \mathrm{e}-002$ & $8.516 \mathrm{e}-006$ & 0.16484 & $3.3291 \mathrm{e}-002$ & $7.9698 \mathrm{e}-007$ & 0.70747 \\
\hline
\end{tabular}

The maximum shear elastic strain of the submarine analyzed at a velocity of 8.09935 knots and comparing with changing the fixed support and increasing collision time from $10000 \mathrm{~s}$ to $1000000 \mathrm{~s}$, found that maximum shear elastic strain is high compare with less collision time

\section{Elastic strain intensity}

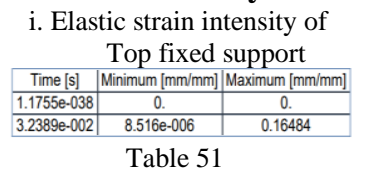

ii. Elastic strain intensity of bottom fixed support

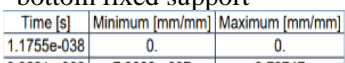

\begin{tabular}{c|c|c|}
\hline $1.1755-0038$ & 0. & 0 \\
\hline $32391+002$ & $79698-007$ & 0.70747 \\
\hline
\end{tabular} Table 52

The elastic strain intensity of the submarine analyzed at a velocity of 8.09935 knots and comparing with changing the fixed support and increasing collision time from $10000 \mathrm{~s}$ to
$1000000 \mathrm{~s}$, found that elastic strain intensity is high compare with less collision time

Comparing the top fixed support at velocity 8.09935 knots with chaining the velocity at 16.1987 knots with bottom fixed support with same collision time $10000 \mathrm{sec}$.

\section{DEFORMATION}

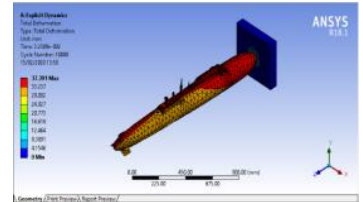

Fig 28.Deformation of Top fixed supports

\begin{tabular}{c|c|c|}
\hline Time $[\mathrm{s}]$ & Minimum [mm] & Maximum [mm] \\
\hline $1.1755 \mathrm{e}-038$ & 0. & 0. \\
\cline { 3 - 3 } $3.2389 \mathrm{e}-002$ & 0.391 \\
& \multicolumn{3}{|c|}{ Table 53 }
\end{tabular}

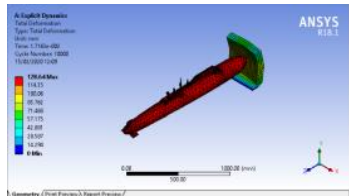

Fig 29.Deformation of Bottom fixed support

\begin{tabular}{|c|c|c|}
\hline $1.1755 \mathrm{e}-038$ & \multirow{2}{*}{0.} & 0. \\
\cline { 3 - 3 } & & 128.64 \\
\hline
\end{tabular}
Table 54 Time [s] Minimum [mm] Maximum [mm]

The deformation of the submarine analyzed at velocity of 8.09935 knots and comparing with changing the fixed support and increasing the velocity to 16.1987 , found that deformation is high in 16.1987 in compare to 8.09935.

\section{Total velocity}

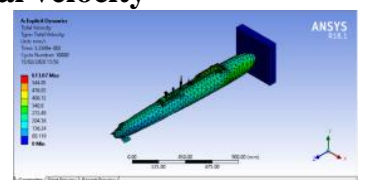

fig 30 total velocity of top fixed support

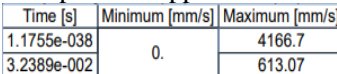

$3.2389 \mathrm{e}-002$

Table 55

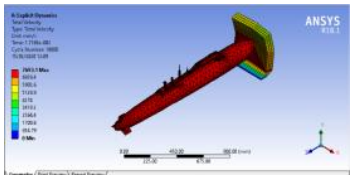

fig 31 . Total velocity of bottom fixed support

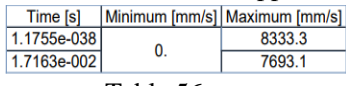

Table 56
The total velocity of the submarine analyzed at velocity of 8.09935 knots and comparing with changing the fixed support and increasing the velocity to 16.1987 , found that total velocity is high in 16.1987 in compare to 8.09935.

Total acceleration

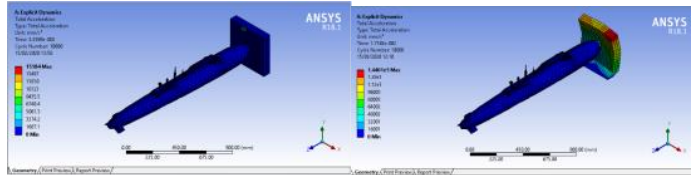

Fig 35.total acceleration of fig 36. Total acceleration of Top fixed support bottom fixed support

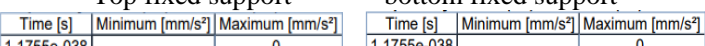

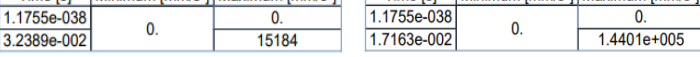

Table $5.57 \quad$ Table 5.58

The total acceleration of the submarine analyzed at velocity of 8.09935 knots and comparing with changing the fixed support and increasing the velocity to 16.1987, found that total acceleration is high in 16.1987 in compare to 8.09935 .

\section{Equivalent elastic stress}

i.Equivalent stress of ii. Equivalent stress of Top fixed support

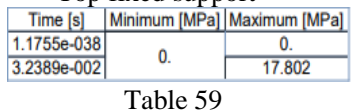
bottom fixed support

\begin{tabular}{|c|c|c|}
\hline Time [s] & Minimum [MPa] & Maximum [MPa] \\
\cline { 3 - 3 } $1.1755 \mathrm{e}-038$ & 0. & 0. \\
\cline { 3 - 3 } & $0.7163 \mathrm{e}-002$ & 3.6118 \\
\hline
\end{tabular}

The total acceleration of the submarine analyzed at velocity of 8.09935 knots and comparing with changing the fixed support and increasing the velocity to 16.1987 , found that total acceleration is low in 16.1987 in compare to 8.09935. 


\section{maximum principal stress}

I.maximum principal stress of ii. Maximum principal stress of top fixed support Bottom fixed support

\begin{tabular}{|c|c|c|c|c|c|}
\hline Time $[s]$ & Minimum [MPa & Maximum [MPa & Time $[s]$ & Minimum [MPa & ] $\mid$ Maximum [MPa] \\
\hline $1.1755 \mathrm{e}-038$ & 0. & 0. & $1.1755 \mathrm{e}-038$ & 0. & 0. \\
\hline $3.2389 \mathrm{e}-002$ & -0.461 & 4.5418 & 1.7163e-002 & -0.35107 & 2.9065 \\
\hline
\end{tabular}

The maximum principal stress of the submarine analyzed at velocity of 8.09935 knots and comparing with changing the fixed support and increasing the velocity to 16.1987 , found that maximum principal stress is low in 16.1987 in compare to 8.09935 .

\section{Minimum principal stress}

\begin{tabular}{|c|c|c|c|c|c|}
\hline \multicolumn{3}{|c|}{$\begin{array}{l}\text { i.Minimum principal stress of } \\
\text { top fixed support }\end{array}$} & \multicolumn{3}{|c|}{$\begin{array}{l}\text { ii. Minimum principal stress of } \\
\text { bottom fixed suppot }\end{array}$} \\
\hline Time [s] & Minimum [MPa] & Maximum [MPa] & Time [s] & Minimum [MPa] & Maximum [MPa] \\
\hline $1.1755 \mathrm{e}-038$ & 0. & 0. & $1.1755 \mathrm{e}-038$ & 0. & 0. \\
\hline $3.2389 \mathrm{e}-002$ & -16.03 & 1.035 & $1.7163 \mathrm{e}-002$ & -2.5876 & 0.44647 \\
\hline
\end{tabular}

Table 63 Table 64

The minimum principal stress of the submarine analyzed at velocity of 8.09935 knots and comparing with changing the fixed support and increasing the velocity to 16.1987 , found that minimum principal stress is low in 16.1987 in compare to 8.09935 .

\section{Maximum shear stress}

\begin{tabular}{l} 
i. Maximum shear stress of \\
Top fixed support \\
\begin{tabular}{|c|c|c|}
\hline Time [s] & Minimum [MPa] & Maximum [MPa] \\
\hline $1.1755 \mathrm{e}-038$ & 0. & 0. \\
\hline $3.2389 \mathrm{e}-002$ & 0.1588 \\
\hline
\end{tabular} \\
\hline
\end{tabular}

ii. Maximum shear stress of bottom fixed support

\begin{tabular}{|c|c|c|}
\hline Time $[\mathrm{s}]$ & Minimum [MPa] & Maximum [MPa] \\
\cline { 1 - 1 } $1.1755 \mathrm{e}-038$ & 0. & 0. \\
\hline $1.7163 \mathrm{e}-002$ & & 2.0816 \\
\hline
\end{tabular}

The maximum shear stress of the submarine analyzed at velocity of 8.09935 knots and comparing with changing the fixed support and increasing the velocity to 16.1987 , found that maximum shear stress is low in 16.1987 in compare to 8.09935

\section{Stress intensity}

\begin{tabular}{|c|c|c|}
\hline \multicolumn{3}{|c|}{$\begin{array}{l}\text { I.stress intensityof } \\
\text { Top fixed support }\end{array}$} \\
\hline Time [s] & Minimum [MPa] & Maximum [MPa] \\
\hline$\frac{1.1755 \mathrm{e}-038}{32389 \mathrm{e}-002}$ & 0. & $\frac{0 .}{18318}$ \\
\hline
\end{tabular}

ii. Stress intensityof
bottom fixed support
\begin{tabular}{|c|c|c|}
\hline Time [s] & Minimum [MPa] & Maximum [MPa] \\
\hline $1.1755 \mathrm{e}-038$ & 0. & 0 \\
\hline $1.7163 \mathrm{e}-002$ & & 4.1632 \\
& Table 68 \\
\hline
\end{tabular}

The stress intensity of the submarine analyzed at velocity of 8.09935 knots and comparing with changing the fixed support and increasing the velocity to 16.1987 , found that stress intensity is low in 16.1987 in compare to 8.09935.

\section{Equivalent elastic strain}

\begin{tabular}{|c|c|c|c|c|c|}
\hline \multirow{2}{*}{\multicolumn{2}{|c|}{$\begin{array}{l}\text { i.Equivalent strain } \\
\text { top fixed support } \\
\text { Time [s] } \\
\text { Minimum [mm/mm] Ma }\end{array}$}} & \multirow{2}{*}{ laximum $[\mathrm{mm} / \mathrm{mm}]$} & \multicolumn{3}{|c|}{$\begin{array}{l}\text { ii. Equivalent strain of } \\
\text { bottom fixed support }\end{array}$} \\
\hline & & & Time [s] $] \mathrm{N}$ & & \\
\hline & 0. & $\begin{array}{l}0 . \\
013297\end{array}$ & $\frac{1.1755 \mathrm{e}-038}{171520 \mathrm{e}-0 .}$ & 0. & $\circ$ \\
\hline & & & & & \\
\hline
\end{tabular}

The equivalent elastic strain of the submarine analyzed at velocity of 8.09935 knots and comparing with changing the fixed support and increasing the velocity to 16.1987, found that equivalent elastic strain is high in 16.1987 in compare to 8.09935 .

\section{Maximum principal elastic strain}

\begin{tabular}{|c|c|c|c|c|c|}
\hline \multicolumn{3}{|c|}{$\begin{array}{l}\text { i. Maximum principal elastic } \\
\text { strain of top fixed support }\end{array}$} & \multicolumn{3}{|c|}{$\begin{array}{l}\text { ii. Maximum principal elastic } \\
\text { strain of bottom fixed support }\end{array}$} \\
\hline Time $[\mathrm{s}]$ & Minimum [mm/mm] & Maximum [mm/mm] & Time $[s]$ & Minimum [mm/mm] & $\operatorname{Maximum}[\mathrm{mm} / \mathrm{mm}]$ \\
\hline $1.1755 \mathrm{e}-038$ & 0 & 0. & 1.1755e-038 & 0. & 0. \\
\hline $3.23899-002$ & $1.2499 \mathrm{e}-006$ & 9.5979e- 002 & $1.7163 \mathrm{e}-002$ & $2.4682 \mathrm{e}-007$ & 1.3162 \\
\hline
\end{tabular}

The maximum principal elastic strain of the submarine analyzed at velocity of 8.09935 knots and comparing with changing the fixed support and increasing the velocity to
16.1987, found that maximum principal elastic strain is high in 16.1987 in compare to 8.09935 .

\section{Minimum principal elastic strain}

\begin{tabular}{|c|c|c|c|c|c|}
\hline \multicolumn{3}{|c|}{$\begin{array}{l}\text { i.Minimum principal elastic } \\
\text { strain of top fixed support }\end{array}$} & \multicolumn{3}{|c|}{$\begin{array}{l}\text { ii. Minimum principal elastic } \\
\text { strain of bottom support }\end{array}$} \\
\hline Time $[\mathrm{s}]$ & Minimum [mm/mm] & Maximum $[\mathrm{mm} / \mathrm{mm}]$ & Time [s] & Minimum [mm/mm] & Maximum [mm/mm] \\
\hline $1.1755 \mathrm{e}-038$ & 0. & 0. & $1.1755 \mathrm{e}-038$ & 0. & 0. \\
\hline $3.2389 \mathrm{e}-002$ & $-8.021 \mathrm{e}-002$ & $9.5222 \mathrm{e}-005$ & $1.7163 \mathrm{e}-002$ & -0.76894 & $3.0546 \mathrm{e}-004$ \\
\hline
\end{tabular}

The minimum principal elastic strain of the submarine analyzed at velocity of 8.09935 knots and comparing with changing the fixed support and increasing the velocity to 16.1987, found that minimum principal elastic strain is high in 16.1987 in compare to 8.09935 .

\section{Maximum shear elastic strain}

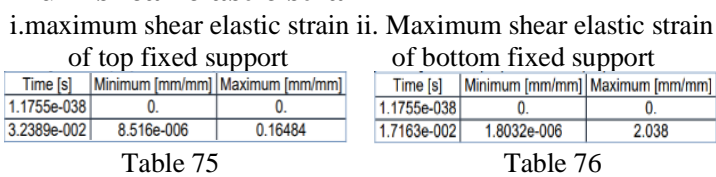

The maximum shear elastic strain of the submarine analyzed at velocity of 8.09935 knots and comparing with changing the fixed support and increasing the velocity to 16.1987 , found that maximum shear elastic strain is high in 16.1987 in compare to 8.09935.

\section{Elastic strain intensity}

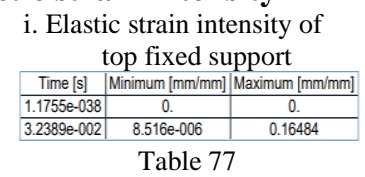

ii. Elastic strain intensity of bottom fixed support

\begin{tabular}{|c|c|c|}
\hline Time $[\mathrm{s}]$ & Minimum [mm/mm] & Maximum [mm/mm] \\
\hline $1.1755 e-038$ & 0. & 0. \\
\hline $1.7163 \mathrm{e}-002$ & $1.8032 \mathrm{e}-006$ & 2.038 \\
\hline \multicolumn{3}{|c|}{ Table 78} \\
\hline
\end{tabular}

The elastic strain intensity of the submarine analyzed at velocity of 8.09935 knots and comparing with changing the fixed support and increasing the velocity to 16.1987 , found that elastic strain intensity is high in 16.1987 in compare to 8.09935 .

The Below tables show the Drag force along the velocities 500, 1000, 1500 at different velocities for Titanium alloy. From the table it is observed that the increasing in the velocity will leads to increase in the Drag Force of the Submarine. And drag coefficient is also increases

Drag force along the velocities of $500,1000,1500$.

\begin{tabular}{|r|r|r|r|}
\hline & \multicolumn{3}{|c|}{ velocity } \\
\hline & 500 & 1000 & 1500 \\
\hline $\begin{array}{c}\text { Drag } \\
\text { force }\end{array}$ & 681705.1 & 2724829 & 4795526 \\
\hline
\end{tabular}

Table 79

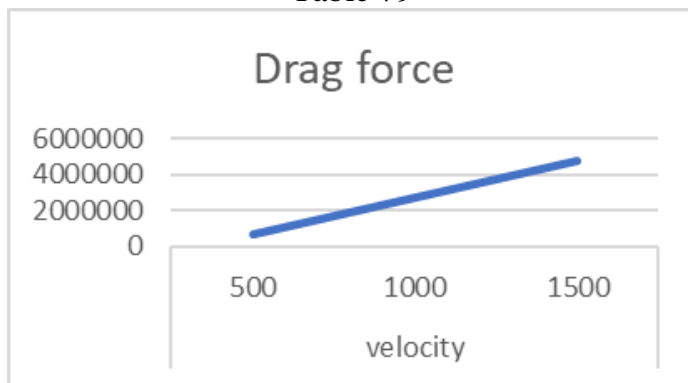

Graph 1 Drag force

Drag Coefficient along the velocities of 500, 1000,1500 .

\begin{tabular}{|r|r|r|r|}
\hline & \multicolumn{3}{|c|}{ velocity } \\
\hline & 500 & 1000 & 1500 \\
\hline $\begin{array}{c}\text { DRAG } \\
\text { COEFF }\end{array}$ & 1112988 & 4448701 & 7829431 \\
\hline
\end{tabular}

Table 80 


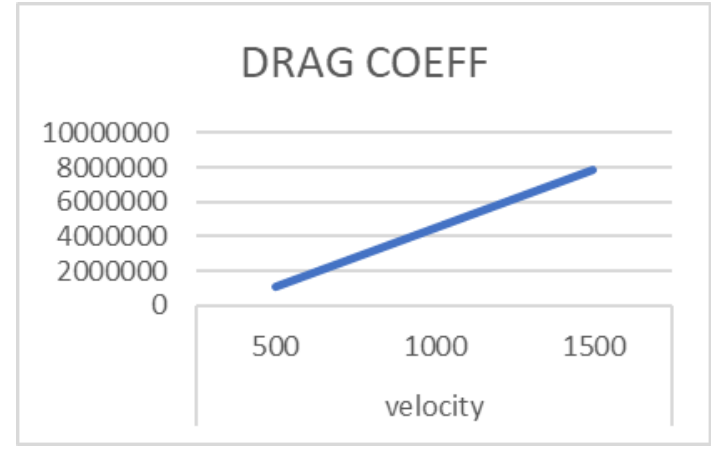

Graph 2 Drag coefficient

Lift Force along the velocities of 500, 1000, 1500 .
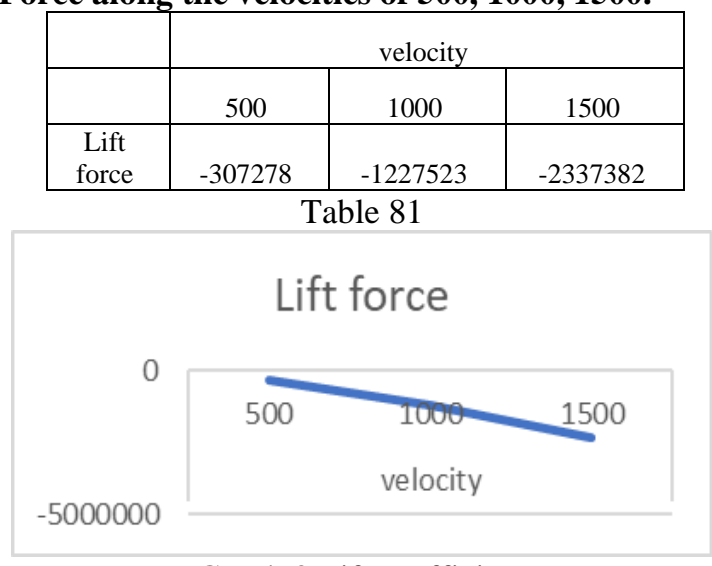

Graph 3 Lift coefficient

Lift Coefficient along the velocities of 500, 1000,1500 .

\begin{tabular}{|c|r|r|r|}
\hline & \multicolumn{3}{|c|}{ velocity } \\
\hline & 500 & 1000 & 1500 \\
\hline Lift & & & \\
COEFF & -501516 & -2004120 & -3816134 \\
\hline
\end{tabular}

Table 82

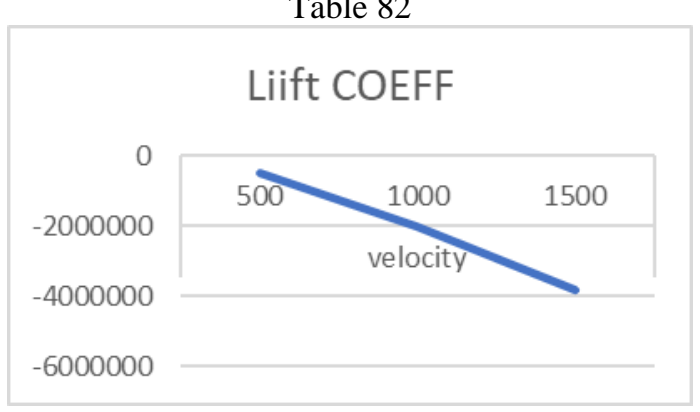

Graph 4 Lift coefficient

In this research the blow tables show the deformations and velocities and accelerations and stress, strains and shows the changes of the occurs on the submarine. In this research we did this compression between changed the Fixed supports with same velocities and increasing the collision time.

\section{Total Deformation}

\begin{tabular}{|c|c|}
\hline $\begin{array}{c}\text { TOP SUPPORT (max } \\
\text { time) }\end{array}$ & $\begin{array}{c}\text { BOTTOM SUPPORT (max } \\
\text { time) }\end{array}$ \\
\hline $3.2390 \mathrm{E}-02$ & $3.3291 \mathrm{E}-02$ \\
\hline 37.391 & 168.5 \\
\hline
\end{tabular}

Table 83

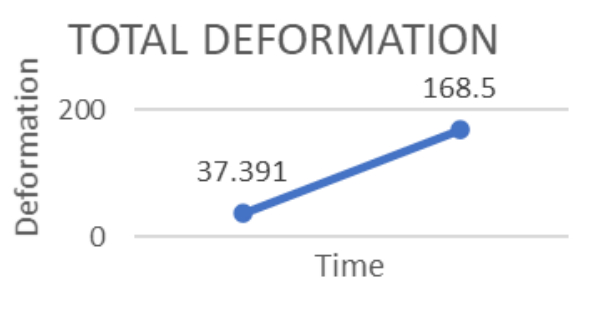

6.6 Total Velocity

Graph 5 Deformation

\begin{tabular}{|c|c|}
\hline $\begin{array}{c}\text { TOP SUPPORT (max } \\
\text { time) }\end{array}$ & $\begin{array}{c}\text { BOTTOM SUPPORT (max } \\
\text { time) }\end{array}$ \\
\hline $3.2390 \mathrm{E}-02$ & $3.3291 \mathrm{E}-02$ \\
\hline 613.07 & 6274.6 \\
\hline
\end{tabular}

TOTAL VELOCITY

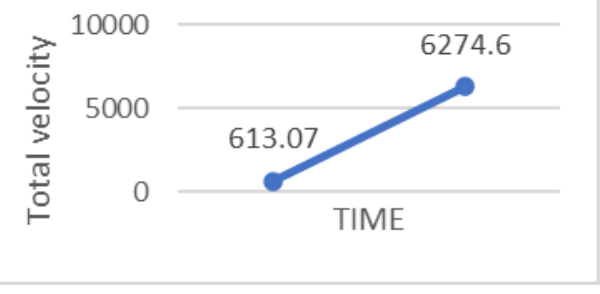

Graph 6 Time vs velocity

(Top vs bottom supports) Total velocity

Total Acceleration

\begin{tabular}{|c|c|}
\hline $\begin{array}{c}\text { TOP SUPPORT } \\
(\text { max time) }\end{array}$ & BOTTOM SUPPORT (max time) \\
\hline $3.2390 \mathrm{E}-02$ & $3.3291 \mathrm{E}-02$ \\
\hline 15184 & $1.41 \mathrm{E}+05$ \\
\hline
\end{tabular}

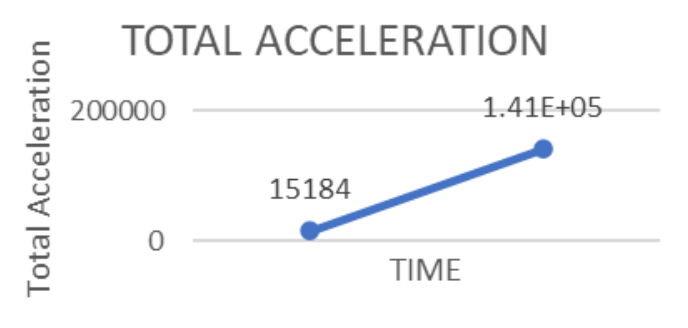

Graph 7 Time vs velocity

(Top vs bottom supports) Total acceleration

Equivalent Elastic Stress

\begin{tabular}{|c|c|}
\hline $\begin{array}{c}\text { TOP SUPPORT } \\
\text { (max time) }\end{array}$ & $\begin{array}{c}\text { BOTTOM SUPPORT } \\
\text { (max time) }\end{array}$ \\
\hline $3.2390 \mathrm{E}-02$ & $3.3291 \mathrm{E}-02$ \\
\hline 17.802 & 9.2819 \\
\hline
\end{tabular}

Table 86

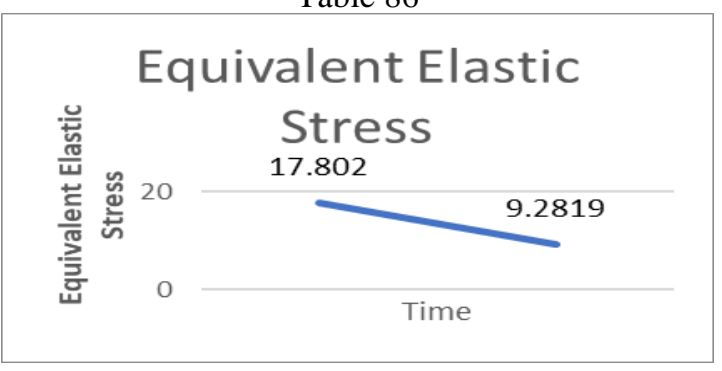

Graph 8 Time vs velocity

(Top vs bottom supports) Equivalent elastic stress 
Maximum principle stress

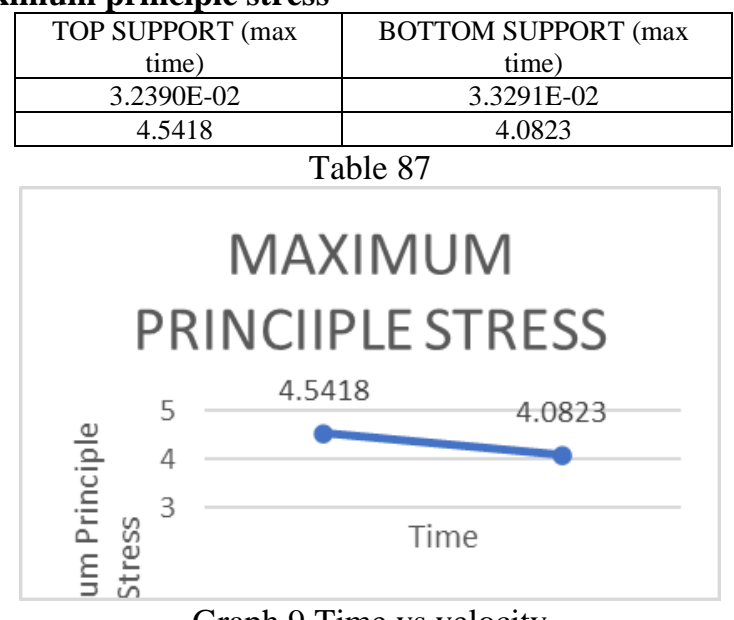

Graph 9 Time vs velocity

(Top vs bottom supports) Maximum principle Stress

\section{Minimum Principle Stress}

\begin{tabular}{|c|c|}
\hline $\begin{array}{c}\text { TOP SUPPORT (max } \\
\text { time) }\end{array}$ & $\begin{array}{c}\text { BOTTOM SUPPORT (max } \\
\text { time) }\end{array}$ \\
\hline $3.2390 \mathrm{E}-02$ & $3.3291 \mathrm{E}-02$ \\
\hline 1.035 & 0.75162 \\
\hline
\end{tabular}

Table 88

\section{Minimum Principle} stress

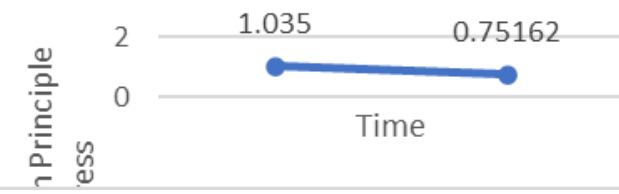

Graph 10 Time vs velocity (Top vs bottom supports) Minimum principle stress

\section{Maximum Shear Stress}

\begin{tabular}{|c|c|}
\hline $\begin{array}{c}\text { TOP SUPPORT (max } \\
\text { time) }\end{array}$ & $\begin{array}{c}\text { BOTTOM SUPPORT (max } \\
\text { time) }\end{array}$ \\
\hline $3.2390 \mathrm{E}-02$ & $3.3291 \mathrm{E}-02$ \\
\hline 9.1588 & 4.8786 \\
\hline
\end{tabular}

Table 89

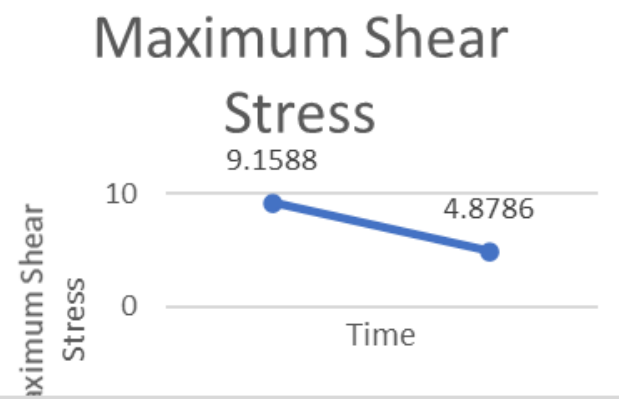

Graph 11 Time vs velocity (Top vs bottom supports) Maximum shear stress

Stress Intensity

\begin{tabular}{|c|c|}
\hline $\begin{array}{c}\text { TOP SUPPORT (max } \\
\text { time) }\end{array}$ & $\begin{array}{c}\text { BOTTOM SUPPORT (max } \\
\text { time) }\end{array}$ \\
\hline $3.2390 \mathrm{E}-02$ & $3.3291 \mathrm{E}-02$ \\
\hline 18.318 & 9.7572 \\
\hline
\end{tabular}

Table 90

\section{Stress Intensity}

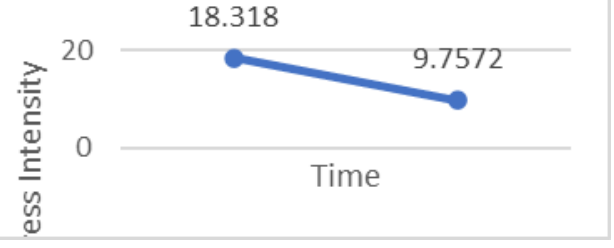

Graph 12 Time vs velocity

(Top vs bottom supports) Stress intensity

\section{Equivalent Elastic Strain}

\begin{tabular}{|c|c|}
\hline $\begin{array}{c}\text { TOP SUPPORT (max } \\
\text { time) }\end{array}$ & $\begin{array}{c}\text { BOTTOM SUPPORT (max } \\
\text { time) }\end{array}$ \\
\hline $3.2390 \mathrm{E}-02$ & $3.3291 \mathrm{E}-02$ \\
\hline 0.13397 & 0.58765 \\
\hline \multicolumn{2}{|c}{ Table 91} \\
\hline
\end{tabular}

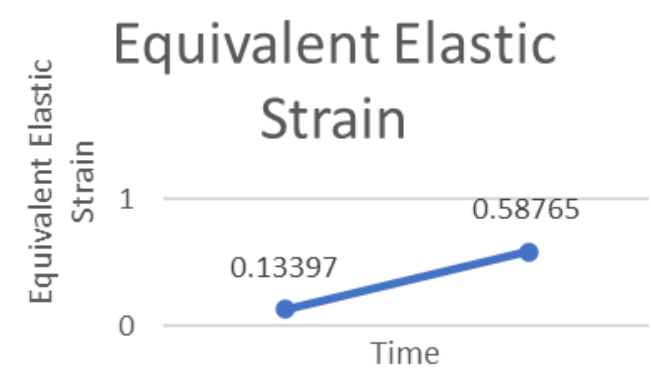

Graph 13(Time vs velocity (Top vs bottom supports) Equivalent elastic strain

Maximum Principle Elastic Strain

\begin{tabular}{|c|c|}
\hline $\begin{array}{c}\text { TOP SUPPORT (max } \\
\text { time) }\end{array}$ & $\begin{array}{c}\text { BOTTOM SUPPORT (max } \\
\text { time) }\end{array}$ \\
\hline $3.2390 \mathrm{E}-02$ & $3.3291 \mathrm{E}-02$ \\
\hline $9.60 \mathrm{E}-02$ & 0.67854 \\
\hline
\end{tabular}

Table 92

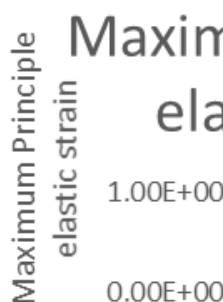

elastic strain

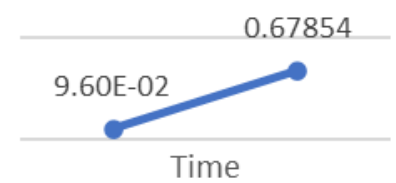

Graph 14 Time vs velocity (Top vs bottom supports) Maximum principle elastic strain

Minimum Principle Elastic Strain

\begin{tabular}{|c|c|}
\hline $\begin{array}{c}\text { TOP SUPPORT (max } \\
\text { time) }\end{array}$ & $\begin{array}{c}\text { BOTTOM SUPPORT (max } \\
\text { time) }\end{array}$ \\
\hline $3.2390 \mathrm{E}-02$ & $3.3291 \mathrm{E}-02$ \\
\hline $9.52 \mathrm{E}-02$ & $2.00 \mathrm{E}-03$ \\
\hline
\end{tabular}

Table 93 


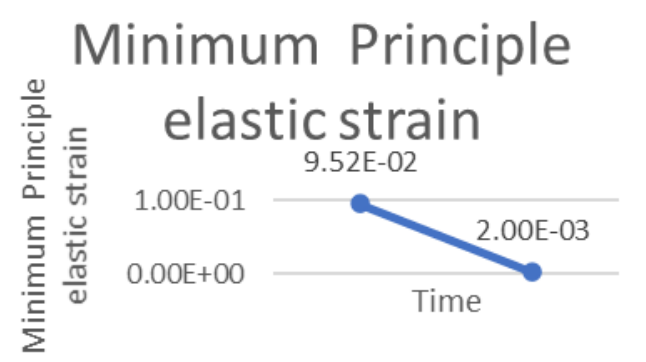

Graph 15 Time vs velocity (Top vs bottom supports) Minimum principle elastic

Maximum Shear Elastic Strain

\begin{tabular}{|c|c|}
\hline $\begin{array}{c}\text { TOP SUPPORT (max } \\
\text { time) }\end{array}$ & $\begin{array}{c}\text { BOTTOM SUPPORT (max } \\
\text { time) }\end{array}$ \\
\hline $3.2390 \mathrm{E}-02$ & $3.3291 \mathrm{E}-02$ \\
\hline 0.16484 & 0.70747 \\
\hline
\end{tabular}

Table 94

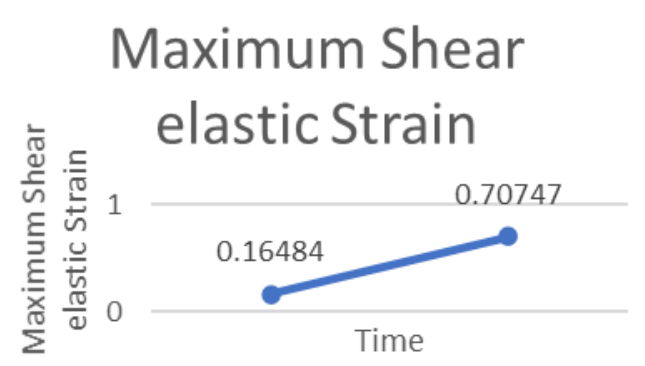

Graph 16 Time vs velocity (Top vs bottom supports) Maximum shear elastic strain

Elastic Strain Intensity

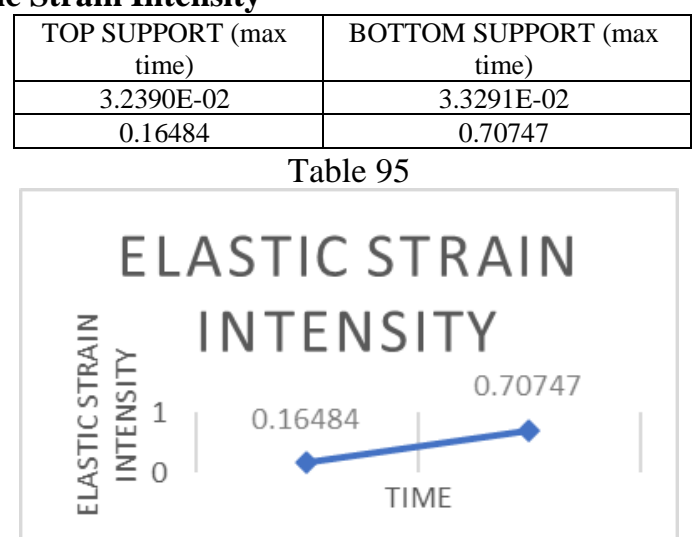

Graph 17 Time vs velocity (Top vs bottom supports) Elastic strain intensity

In this research the blow tables show the deformations and velocities and accelerations and stress, strains and shows the changes of the occurs on the submarine. In this research we did this compression between changed the Fixed supports with changed the velocities and increasing the collision time.

\section{Total Deformation}

\begin{tabular}{|c|c|}
\hline TOP SUPPORT & BOTTOM SUPPORT \\
\hline 8.09935 knots & 16.1987 knots \\
\hline 37.391 & 128.64 \\
\hline
\end{tabular}

Table 96

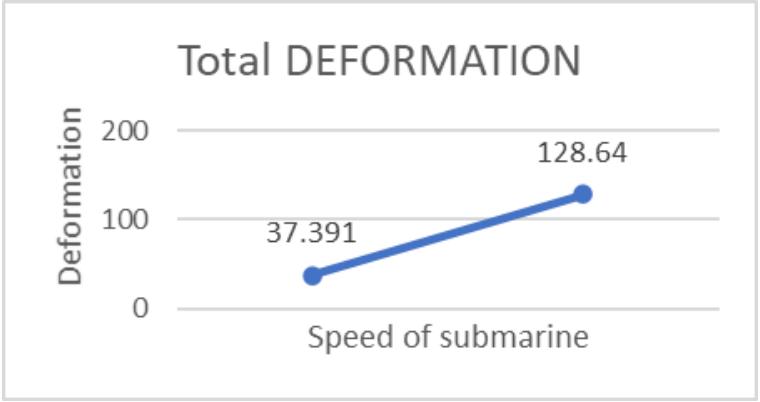

Graph 18 Time vs velocity (Top vs bottom supports) Total deformation

Total Velocity

\begin{tabular}{|c|c|}
\hline TOP SUPPORT & $\begin{array}{l}\text { BOTTOM } \\
\text { SUPPORT }\end{array}$ \\
\hline 8.09935 knots & 16.1987 knots \\
\hline 613.07 & 7693.1 \\
\hline
\end{tabular}

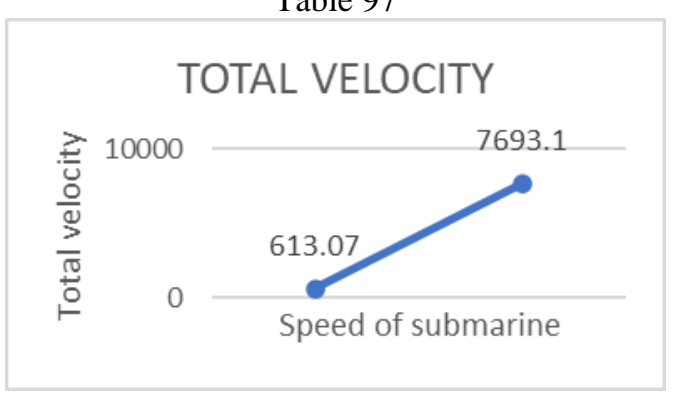

Graph 19 Time vs velocity (Top vs bottom supports) Total velocity

6.20 Total Acceleration

\begin{tabular}{|c|c|}
\hline TOP SUPPORT & BOTTOM SUPPORT \\
\hline 8.09935 knots & 16.1987 knots \\
\hline 15184 & $1.44 \mathrm{E}+09$ \\
\hline & Table 98 \\
\hline
\end{tabular}

\section{TOTAL ACCELERATION}

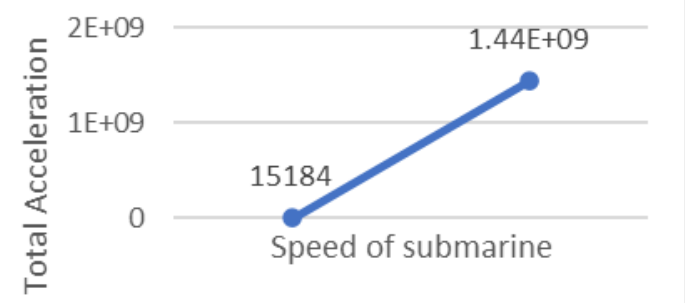

Graph 20 Time vs velocity (Top vs bottom supports) Total acceleration

\section{Equivalent Elastic Stress}

\begin{tabular}{|c|c|}
\hline TOP SUPPORT & BOTTOM SUPPORT \\
\hline 8.09935 knots & 16.1987 knots \\
\hline 17.802 & 3.6118 \\
\hline
\end{tabular}

Table 99 


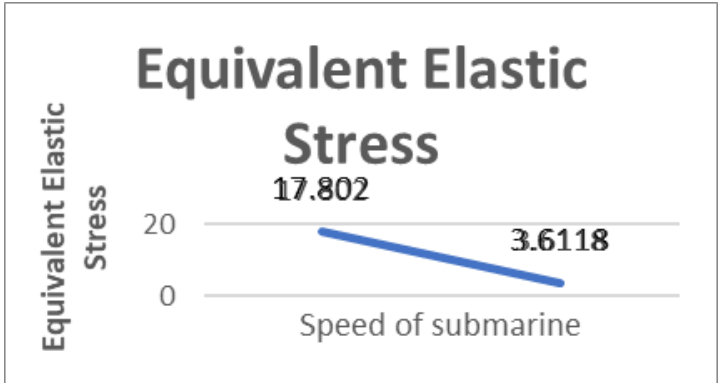

Graph 21 Time vs velocity (Top vs bottom supports) Equivalent elastic stress

Maximum Elastic Stress

\begin{tabular}{|c|c|}
\hline TOP SUPPORT & BOTTOM SUPPORT \\
\hline 8.09935 knots & 16.1987 knots \\
\hline 4.5418 & 2.9065 \\
\hline
\end{tabular}

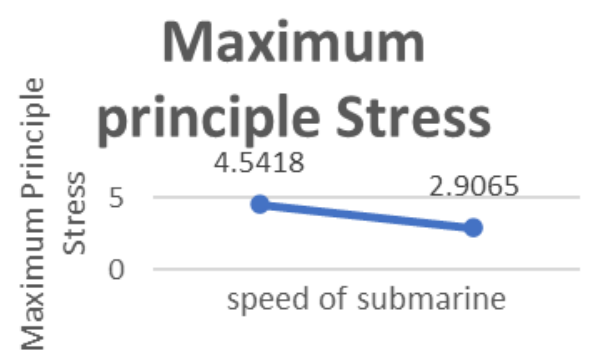

Graph 22 Time vs velocity (Top vs bottom supports) maximum Principle stress

Minimum Principle Stress

\begin{tabular}{|c|c|}
\hline TOP SUPPORT & BOTTOM SUPPORT \\
\hline 8.09935 knots & 16.1987 knots \\
\hline 1.035 & 0.44647 \\
\hline \multicolumn{2}{|c|}{ Table 101} \\
\hline
\end{tabular}

\section{Minimum Principle}

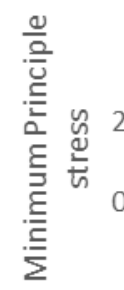
stress

$2 \longdiv { 1 . 0 3 5 }$

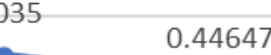

Speed of Submarine

Graph 23 Time vs velocity (Top vs bottom supports)

Minimum principle stress

Maximum Shear Stress

\begin{tabular}{|c|c|}
\hline TOP SUPPORT & BOTTOM SUPPORT \\
\hline 8.09935 knots & 16.1987 knots \\
\hline 9.1588 & 2.0816 \\
\hline
\end{tabular}

Time vs Velocity different fixed supports

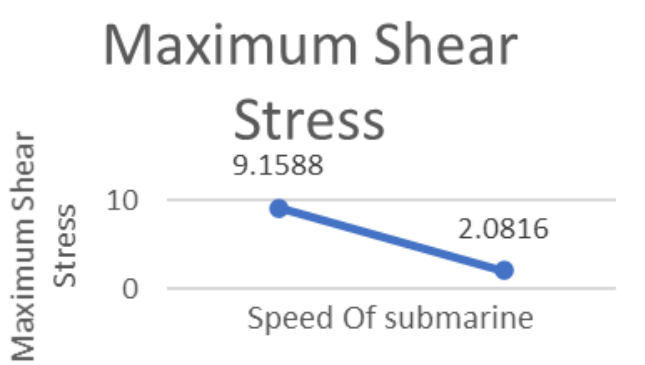

Graph 24 Time vs velocity (Top vs bottom supports) Maximum shear stress

Stress Intensity

\begin{tabular}{|c|c|}
\hline TOP SUPPORT & BOTTOM SUPPORT \\
\hline 8.09935 knots & 16.1987 knots \\
\hline 18.318 & 4.1632 \\
\hline
\end{tabular}

Table 103

\section{Stress Intensity}

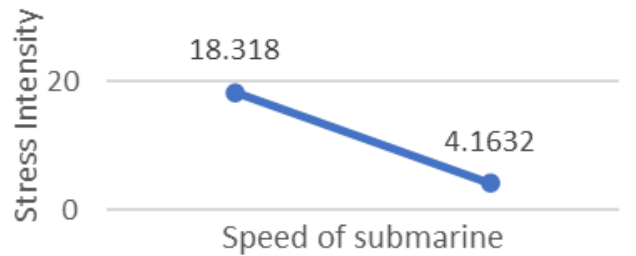

Graph 25 Time vs velocity (Top vs bottom supports) Stress intensity

6.26 Equivalent Elastic Strain

\begin{tabular}{|c|c|}
\hline TOP SUPPORT & BOTTOM SUPPORT \\
\hline 8.09935 knots & 16.1987 knots \\
\hline 0.13397 & 1.5166 \\
\hline
\end{tabular}

Table 104

\section{Equivalent Elastic}

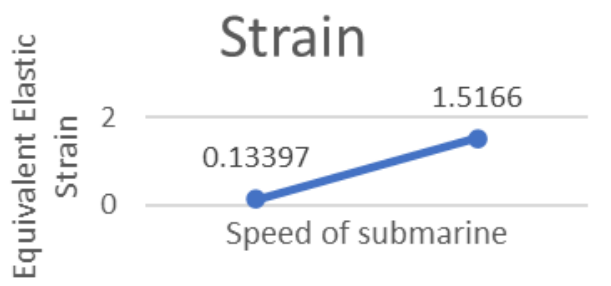

Graph 26 Time vs velocity (Top vs bottom supports)

Equivalent elastic strain

Maximum Principle Elastic Strain

\begin{tabular}{|c|c|}
\hline TOP SUPPORT & BOTTOM SUPPORT \\
\hline 8.09935 knots & 16.1987 knots \\
\hline $9.60 \mathrm{E}-02$ & 1.3162 \\
\hline
\end{tabular}




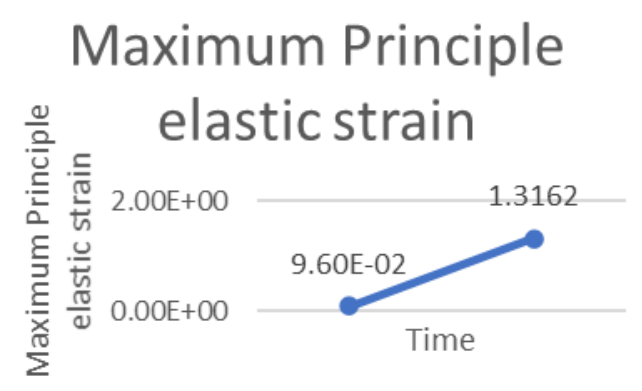

Graph 27 Time vs velocity (Top vs bottom supports) maximum principle elastic strain

Minimum Principle Elastic Strain

\begin{tabular}{|c|c|}
\hline TOP SUPPORT & BOTTOM SUPPORT \\
\hline 8.09935 knots & 16.1987 knots \\
\hline $9.52 \mathrm{E}-02$ & $3.05 \mathrm{E}-04$ \\
\hline \multicolumn{2}{|c}{ Table 106} \\
\hline
\end{tabular}

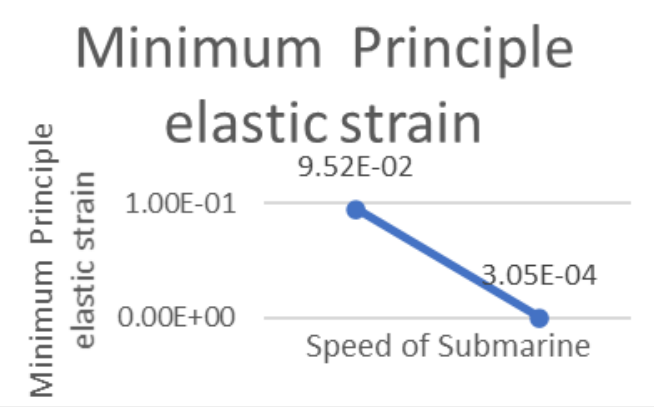

Graph 28 Time vs velocity (Top vs bottom supports) minimum principle

Maximum Shear Elastic Strain

\begin{tabular}{|c|c|}
\hline TOP SUPPORT & BOTTOM SUPPORT \\
\hline 8.09935 knots & 16.1987 knots \\
\hline 0.16484 & 2.038 \\
\hline \multicolumn{3}{|c}{ Table 107} \\
\hline
\end{tabular}

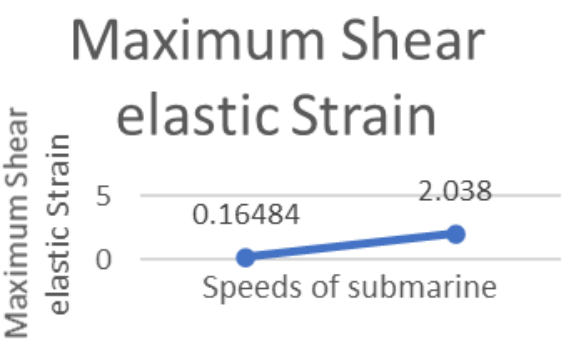

Graph 29 Time vs velocity (Top vs bottom supports) maximum shear elastic strain

Elastic Strain Intensity

\begin{tabular}{|c|c|}
\hline TOP SUPPORT & BOTTOM SUPPORT \\
\hline 8.09935 knots & 16.1987 knots \\
\hline 0.16484 & 2.038 \\
\hline \multicolumn{2}{|c|}{ Table 108} \\
\hline
\end{tabular}

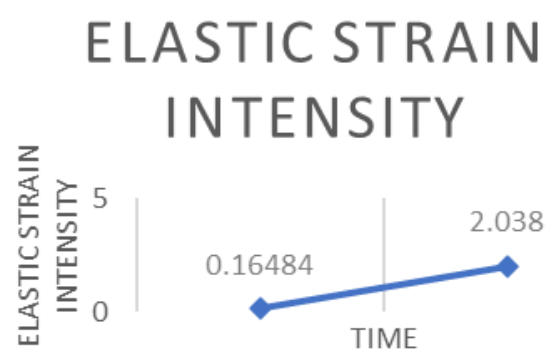

Graph 30 Time vs velocity (Top vs bottom supports) Elastic strain intensity

CONCLUSION

It is observed that when submarine collision test with some object in under water with a velocity the deformations and stress and strain which are occurred on submarine and find the drag and lift on the submarine.

In this research work of Computational Fluid Dynamics, the Drag force and drag coefficient, is gradually increases when the velocities are increases from 500 to 1500, Lift coefficient and lift force is decreasing when the velocity increases from 500 to 1500

Using explicit dynamics the collision test did on the submarine with the velocity of $8.09935(15 \mathrm{kmph})$ knots with variable fixed supports of both top and bottom supports and only top fixed support and collision time is same $\mathbf{1 0 0 0 0}$ $\mathbf{s}$ ), and found that there is no change in deformations, velocities, accelerations, Equivalent stress, maximum principal stress, minimum principal stress, stress intensity, Equivalent elastic strain, maximum principal elastic strain, minimum principal elastic strain, maximum shear elastic strain, strain intensity There is No effect on submarine with changing the fixed support.

Due to that we compare that submarine collision test with velocity (8.09935 Knots) and compare with top fixed support and bottom fixed support and increasing collision time (time from $10000 \mathrm{~s}$ to $1000000 \mathrm{~s}$ ) the Total Deformation and Total velocity also increases but acceleration decreases. In stress we found Equivalent stress, minimum principal stress, stress intensity is same, but the maximum principal stress is increased. In strains we found Equivalent elastic strain, maximum principal elastic strain, minimum principal elastic strain, maximum shear elastic strain, strain intensity all strains are high compared to previous collision time.

When we compare this collision test with changing the velocity from 8.09935 knots to 16.1987 knots with bottom fixed support with collision time $(\mathbf{1 0 0 0 0} \mathbf{s})$ the deformations, velocities and accelerations are high compared to the $15 \mathrm{kmph}$ and in the stress we found equivalent stress, maximum principal stress, minimum principal stress, stress intensity all are low compared to the 8.09935 knots speed collision. In strains we found Equivalent elastic strain, maximum principal elastic strain, minimum principal elastic strain, maximum shear elastic strain, strain intensity all strains are high compare to 8.09935 knots. 


\section{REFERENCE:}

[1] Malcolm J. Smitha, Tom Macadamb and John R. MacKaya 2014, Integrated modelling, design and analysis of submarine structures.

[2] Khairul Ala, Tapabrata Ray and Sreenatha G. Anavatti 2013, Design and construction of an autonomous underwater vehicle

[3] Tomislav ŠABALJA, Ivo SENJANOVIĆ, Neven HADŽIĆ, structural design of a typhoon class submarine

[4] Mark C. Bettle a, Andrew G. Gerber a, George D. Watt b 2009 Unsteady analysis of the six DOF motion of a buoyantly rising submarine

[5] ADITYA CHIVATE, SAURABH KHUJE, SHUBHAM VINCHURKAR, ANUJIT DAFLE, 2018, design and optimization of an underwater vessel for speed augmentation using CFD

[6] A. Vali, B. Saranjam and R. Kamali, 2018 Experimental and Numerical Study of a Submarine and Propeller Behaviors in Submergence and Surface Conditions

[7] K. Jaswanth, B. Geeta Chandra Sekhar, R.Vara Prasad, Flow and Crash Analysis of an F-16 Aircraft Using ANSYS

[8] Douglas R. Knight, Donald V. Tappan, Jeffry S. Bowman, Hugh J. O Neil and S.M. Gordon, 1989, Submarine atmospheres

[9] M. N. Norwooda and R. S. Dowb, 2012, Dynamic analysis of ship structures

[10] Mohammad Moonesun, Yuri Mikhailovich Korol, Hosein Dalayeli, 2015, CFD Analysis on the Bare Hull Form of Submarines for Minimizing the Resistance

[11] M. Moonesun Y.M. Korol and A. Brazhko 2015 CFD analysis on the equations of submarine stern shape

[12] Mohammad Moonesun, Yuri Mikhailovich Korol, Valeri A Nikrasov, Alexander Ursalov, Anna Brajhko, 2016 CFD Analysis of the bow shapes of submarines

[13] Mohammad Monesun, Mehran javidi, pejman charmdooz \& karol uri Mikhailovich, 2013 CFD analysis of the bow shapes of submarines

[14] G. Dubbioso, R. Broglia, S. Zaghi, 2016 CFD analysis of turning abilities of a submarine model

[15] Gita Marina Ahadyanti, Wasis Dwi Aryawan, and Muhamad Fyan Dinggi, 2017, Submerged resistance analysis of mini submarine using computational fluid dynamics

[16] Suman Kar, D.G. Sarangdhar \& G.S. Chopra, Analyses of ship structures using Ansys

[17] Jeong-Hoon Song, Patrick Lea, and Jay Oswald, 2013, Explicit Dynamic Finite Element Method for Predicting Implosion/Explosion Induced Failure of Shell Structures 